\title{
RELATIONSHIP BETWEEN TOTAL LENGTH AND DIGESTIVE TRACT OF DIFFERENT CARNIVOROUS FISHES
}

\author{
M. M. Rahman, M. M. M. Alam ${ }^{1 *}$ and T. Zaman ${ }^{2}$ \\ Deputy Coordinator, Youth Training Centre, Department of Youth and Sports, Bangladesh
}

\begin{abstract}
The study was conducted to find out the relationship between total length and alimentary canal of different carnivorous fishes. The morphometry associated with the feeding and digestion of one hundred eighty fishes of 9 species was studied. It was observed that well-defined sharp teeth were present on both jaws of the fishes examined. It was also found that the fishes had rough surface pharyngeal pads. The total length of Johnius koitor, Channa orientalis, Channa punctatus, Mvstus vittatus, Glossogobius giuris, Nandus nandus, Eleotris fusca and Anabas testudineus were 1.28 to $1.72,2.90$ to $3.17,2.22$ to $2.70,2.00$ to $2.40,3.00$ to $4.50,1.20$ to $1.50,1.40$ to 2.36 and 1.48 to 1.64 times greater than the intestinal length, respectively and the intestinal lengths were 5.45 to $6.02,1.30$ to $1.70,1.70$ to $2.10,3.60$ to $4.10,2.10$ to $2.50,2.90$ to $3.20,2.00$ to 12.00 and 3.00 to 5.30 times longer than the stomach of the fishes, respectively. The total length of Xenontodon cancila was 9.20 to 9.80 times greater than the intestinal length and the stomach length was 1.90 to 2.20 times greater than the intestinal length with an average of 2.00 times.
\end{abstract}

Key Words: Body length, Digestive tract, Carnivorous fish

\section{INTRODUCTION}

Bangladesh, the World largest river-delta, possesses diversified aquatic resources. Fisheries resources play important roles in the economy, culture, traditions and food habit of the people of Bangladesh. It is endowed with highly separate inland aquatic ecosystems such as river, canal, haor, baor, beel, lake and ditches (DoF, 1995), which are enriched with about 260 indigenous fish species (Rahman, 1989). Among the fish species only 5 to 7 species are introduced to culture, but the rest of the fishes are in very negligible conditions. Moreover, due to overfishing and different man-made and natural reasons, fish diversity has been hampered triggering many fishes to be endangered. To prevent the endangered fishes from extinction and to protect aquatic biodiversity, nine endangered species in Bangladesh such as Johnius koilor, Channa orientalis, Channa punctatus, Mystus vittatus, Xenontodon cancila, Glossogobius giuris, Nandus nandus, Eleotris fusca and Anabas testudineus have been selected for investigation. The information on the morphology and the feeding habits of mentioned fishes is not available. Therefore, an experiment was conducted to

\footnotetext{
1 Upazila Fisheries Officer, Department of Fisheries, Bangladesh

2 Deputy Coordinator, Youth Training Centre, Department of Youth and Sports, Bangladesh

Corresponding Author:- E-mail: mhbb_alam@yahoo.com
} 
study the morphology of digestive systems to establish a relationship between the body length and the gut length of the fishes.

\section{MATERIALS AND METHODS}

\section{Selection of the fish species}

Nine freshwater fish species were selected depending on their availability and importance. The fishes were J. koitor, C. orientales, C. punctatus, which are closely related in their body shape, known as koitor, raga and lata, respectively. The other fish species were $M$. vittatus, $X$. cancila, G. giuris, N. nandus, E. fusca and A. testudineus are locally known as tengra, kakila, bele, bheda, boiragi or culti and koi respectively. These fishes are popular in SouthEast Asia and once they were abundant in freshwaters of Bangladesh. They are delicious and have good market demand.

\section{Collection of fishes}

The fishes were collected from the local markets of Bangladesh. Most of the fish species were collected in fresh condition from Mymensingh fish market, but only two species i.e., J. koitor and E. fusca were collected from Barishal region of Bangladesh. Twenty individuals of different sizes of each species were collected.

\section{Duration of study}

The study was performed for a period of two months from July to August 1998 in the laboratory of the Department of Aquaculture, Faculty of Fisheries, Bangladesh Agricultural University, Mymensingh, Bangladesh.

\section{Morphological study}

One hundred eighty individuals of 9 species, 20 of each species, were examined during the study. Fish species were measured with a scale graduated upto $0.5 \mathrm{~mm}$. The total length (TL) and standard length (SL) of the fishes were recorded very carefully by placing them horizontally on the scale. Diameter of Eyes (DE) of each fish was also recorded. An incision was made through body wall in mid-ventral line opposite to base of the pectoral fin by fine scissors. The one side of the body cavity was removed by another incision along the tipper boundary of the body cavity. Then the body cavity was exposed and washed carefully to observe the coiling pattern of intestine and to find out the location where stomach was connected with the intestine. Then the intestine and stomach were removed carefully and decoiled not to puncture and cut down into pieces and the intestine and stomach made separate. Then these were separately placed on a horizontal desk and measured with a millimeter scale. The stomach length (SmL) and intestine length (ItL) were recorded from every individual fishes.

Then the mouth was opened by an incision from forepart (oesophagus) of the stomach to the mouth opening and the length of the mouth and oesophagus were measured. The type of mouth, pharyngeal teeth and their arrangement, sharpness of teeth (sharp or blunt) and 
pharyngeal pad were also observed. Simultaneously, the condition of digestive tracts like stomach, oesophagus and different parts of intestine with their coiling pattern of all the experimental fishes were observed.

\section{Data analysis}

Data were presented here as range value or mean \pm SD. The relationship between TL and SmL or TL and ItL were carried out by regression co-efficient method using MS Excel.

\section{RESULTS}

\section{Johnius koitor}

Twenty fish samples of $J$. koitor ranging from $11.0 \mathrm{~cm}$ to $17.40 \mathrm{~cm}$ in total length were studied. The mouth type of the fish was terminal. Both lips were somewhat equally prolonged and furnished with very dense fine teeth in both of the jaws. The pharynx was short in size and pharyngeal pad contains very short and few number of teeth. A hand muscular cushion with rough surface was found immediately beneath the pharyngeal teeth and on the floor of the pharynx known as pharyngeal pad. Structurally oesophagus was observed to comprise the hind part of the total alimentary canal. It was comparatively thick and with a rough inner surface. Immediately after the oesophagus a stomach of slightly swollen and tubular shaped was present. Intestine was observed originated from the post part to the stomach and reached near to the anus. The arrangement of the intestine was in such a manner that it formed tubular shaped structure with a bend at the mid part of the intestine.

The TL, SL, ED, SmL and ItL of the fishes examined were $14.72 \pm 1.87,11.64 \pm 1.53,0.44 \pm$ $0.09,1.73 \pm 0.35$ and $10.24 \pm 2.72$, respectively (Table 1 ). It was observed that the TL was 1.28 to 1.72 times greater than that of the ItL of the fish and ItL was 5.45 to 6.02 times greater than that of the SmL.

The regression equation of TL and SmL was $\mathrm{Y}=-0.095+0.125 \times \mathrm{X} \ldots \ldots$... I $)$

The equation of TL and ItL was $Y=-10.226+1.390 \times X$

Where, $Y=S m L$ for equation (I) and ItL for equation (II); $X=T L$.

\section{Channa orientalis}

Twenty individuals of raga, C. orientalis ranging from $6.0 \mathrm{~cm}$ to $16.5 \mathrm{~cm}$ in TL were studied to determine die relationship of total length and intestinal length and to observe the digestive systems. The mouth type of the fish was blunt both lips were more or less in equal position. Short and blunt teeth were present in both the jaws. The pharynx was comparatively long in size with a thicker wall. The ED of the fish was ranged from $0.25 \mathrm{~cm}$ to $0.55 \mathrm{~cm}$ in size. The morphological structures of the alimentary canal of all the fishes studied were same although some variations were observed due to size difference. However, oesophagus was observed to comprise the smallest part of the alimentary canal. It was comparatively thick and with a rough inner surface. Immediately after the oesophagus sac liked and slightly swollen stomach was present. Intestine was observed 
originated from the forepart of the stomach and positioned at the right side of the stomach. The intestine was tubular and 'S' shaped structure.

Table 1. Mean Values $( \pm \mathrm{SD}$ ) of Total Length (TL), Standard Length (SL), Eye Diameter (ED), Stomach Length (SmL) and Intestine Length (ItL) of the fishes examined

\begin{tabular}{l|c|c|c|c|c}
\hline \multicolumn{1}{c|}{ Fish Species } & $\begin{array}{c}\text { Mean } \\
\text { TL }( \pm \text { SD }) \\
(\mathrm{cm})\end{array}$ & $\begin{array}{c}\text { Mean } \\
\text { SL }( \pm \text { SD }) \\
(\mathrm{cm})\end{array}$ & $\begin{array}{c}\text { Mean } \\
\text { ED }( \pm \text { SD }) \\
(\mathrm{cm})\end{array}$ & $\begin{array}{c}\text { Mean } \\
\text { Stomach } \\
\text { Length } \\
( \pm \mathrm{SD})(\mathrm{cm})\end{array}$ & $\begin{array}{c}\text { Mean } \\
\text { Intestine } \\
\text { Length } \\
( \pm \mathrm{SD})(\mathrm{cm})\end{array}$ \\
\hline Johnius koitor & $14.72 \pm 1.87$ & $11.64 \pm 1.53$ & $0.44 \pm 0.09$ & $1.73 \pm 0.35$ & $10.24 \pm 2.72$ \\
Channa orientalis & $11.68 \pm 2.72$ & $9.82 \pm 2.36$ & $0.40 \pm 0.08$ & $2.51 \pm 0.82$ & $3.80 \pm 0.61$ \\
Channa punctatus & $11.35 \pm 2.16$ & $9.44 \pm 1.86$ & $0.41 \pm 0.09$ & $2.13 \pm 0.61$ & $4.12 \pm 0.62$ \\
Mystus vittatus & $10.02 \pm 0.82$ & $7.90 \pm 0.72$ & $0.32 \pm 0.04$ & $1.19 \pm 0.19$ & $4.55 \pm 0.70$ \\
Xenentodon cancila & $17.62 \pm 3.12$ & $16.25 \pm 2.88$ & $0.53 \pm 0.08$ & $3.34 \pm 1.01$ & $1.85 \pm 0.44$ \\
Glossogobius giuris & $9.80 \pm 2.82$ & $8.15 \pm 2.84$ & $0.33 \pm 0.09$ & $1.36 \pm 0.32$ & $3.00 \pm 0.81$ \\
Nandus nandus & $9.63 \pm 1.57$ & $7.94 \pm 1.3$ & $0.52 \pm 0.06$ & $1.98 \pm 0.60$ & $7.03 \pm 1.49$ \\
Eleotris fusca & $7.62 \pm 0.75$ & $6.23 \pm 0.68$ & $0.20 \pm 0.01$ & $0.86 \pm 0.19$ & $4.93 \pm 0.88$ \\
Anabas testudineus & $9.39 \pm 1.30$ & $7.69 \pm 1.00$ & $0.44 \pm 0.06$ & $1.83 \pm 0.41$ & $5.98 \pm 0.93$ \\
\hline
\end{tabular}

The TL, SL, ED, SmL and ItL of the fishes examined were $11.68 \pm 2.72,9.82 \pm 2.36,0.40 \pm$ $0.08,2.51 \pm 0.82$ and $3.80 \pm 0.61$, respectively (Table 1 ). The relationship between TL and ItL, and SmL and ItL were recorded. It was observed that the TL was 2.90 to 3.17 times greater than the ItL of the fish. The ItL was 1.30 to 1.70 times greater than that of the SmL of the fish.

The regression equation of TL and SmL was $Y=-0.857+0.265 \times X \ldots$ (III)

The regression equation of TL and ItL was $Y=1.482+0.199 \times X \ldots$ (IV).

Where, $\mathrm{Y}=\mathrm{SmL}$ for equation (III) and ItL for equation (IV); $\mathrm{X}=\mathrm{TL}$.

\section{Channa punctatus}

Table 1 shows the mean values of TL, SL, ED, SmL and ItL. The morphological structure of digestive systems was closely related to $C$. orientalis. The mouth type of the fish was slightly prolonged. The eye diameter of the fishes were observed and found ranging from $0.30 \mathrm{~cm}$ to $0.60 \mathrm{~cm}$. Both the jaws were terminal, strong and sharp. Fine teeth were present in both the jaws. Pharyngeal teeth were present with rough pharyngeal pad. The oesophagus was observed as the hind part of the total alimentary canal. It was thick with a rough inner surface. The stomach was of sac like and thick walled originated immediately after the oesophagus. The intestine was tubular and ' $\mathrm{S}$ ' shaped with short and few numbers of teeth. The eye diameters ranged from $0.30 \mathrm{~cm}$ to $0.70 \mathrm{~cm}$. The alimentary canal of all the fishes studied were same with different sizes. The oesophagus was comperatively thick with a rough inner surface. Immediately after the oesophagus a sac like stomach ran through out the body cavity. The intestine originated from its fore part 
and reached upto the anus. The intestine was double ' $U$ ' shaped attached to the stomach with its lateral position. The fore part of the intestine was thick while the posterior one was thin.

The TL, SL, ED, SmL and ItL of the fishes examined were $11.35 \pm 2.16,9.44 \pm 1.86,0.41 \pm$ $0.09,2.13 \pm 0.61$ and $4.12 \pm 0.62$, respectively (Table 1 ). It was observed that the TL was 2.22 to 2.70 times greater than the ItL of the fish with an average of 2.50. The ItL was 1.70 to 2.10 times greater than that of the SmL of the fish.

The regression equation between TL and SmL was $Y=-0.063+0.205 \times X(V)$.

The regression equation between $\mathrm{TL}$ and ItL was $\mathrm{Y}=0.534+0.242 \times \mathrm{X} \ldots(\mathrm{VI})$.

Where, $Y=S m L$ for equation $(V)$ and ItL for equation $(\mathrm{VI}) ; \mathrm{X}=\mathrm{TL}$.

\section{Mystus vittatus}

The fishes were ranged from $8.30 \mathrm{~cm}$ to $11.90 \mathrm{~cm}$ in total length. The mouth type was blunt but dorsoventrally flattened, both the jaws contains strong blunt teeth. Mat like pharyngeal pad was present and pharyngeal teeth were not so prominent, eye diameter was ranged from $0.30 \mathrm{~cm}$ to $0.40 \mathrm{~cm}$. The mouth cavity was slightly elongated towards the pharynx. The pharynx was short in size and it possessed pharyngeal teeth. The oesophagus was observed to comprise the first and the least part of the total alimentary canal which was thick and its inner surface was very rough. After the oesophagus slightly swollen elongated stomach was present. The intestine was originated from the joining portion between the oesophagus and the stomach. The intestine was tubular shaped with no coiling pattern but one at the middle of the intestine. The diameter of the intestine was same from the fore part till the hind part.

The TL, SL, ED, SmL and ItL of the fishes examined were $10.02 \pm 0.82,7.90 \pm 0.72,0.32 \pm$ $0.04,1.19 \pm 0.19$ and $4.55 \pm 0.70$, respectively (Table 1 ). The TL was 2.00 to 2.40 times larger than that of the ItLof the fish. The ItL was 3.60 to 4.10 times greater than that of SmL of the fish. The regression equation between TL and SmL was $\mathrm{Y}=-0.614+0.181 \times \mathrm{X} \ldots .$. (VII).

The regression equation between TL and ItL was $\mathrm{Y}=-0.955+0.549 \times \mathrm{X} \ldots \ldots$ (VIII). Where, $\mathrm{Y}=\mathrm{SmL}$ for equation (VII) and ItL for equation (VIII); $\mathrm{X}=\mathrm{TL}$.

\section{Xenentodon cancila}

The fishes were varied from $10.50 \mathrm{~cm}$ to $23.40 \mathrm{~cm}$ in total length. The mouth of the fish was long beak like structure, which was found to be narrow strong and pointed. Both the jaws were not equal in size, but the upper jaws were slightly longer than that of the lower one. The beak like jaws possess hard numerous and very fine teeth. The eye diameters were ranged from $0.40 \mathrm{~cm}$ to $0.60 \mathrm{~cm}$. The pharyngeal regions of the fishes were very smooth, but mouth cavity found very large in size. The oesophaguses of the fishes were also observed which was elastic in nature, slightly swollen and elongated stomach was present just after the oesophagus. The stomach was also a tube like structured but slightly flattened in the middle portion. The intestine was very short and straight than that of the 
other fishes and also no coiling patterns were observed from fore part to anus. But the stomach and intestine both were very thick walled and the posterior part of intestine was comparatively thin.

The TL, SL, ED, SmL and ItL of the fishes examined were $17.62 \pm 3.12,16.25 \pm 2.88,0.53 \pm$ $0.08,3.34 \pm 1.01$ and $1.85 \pm 0.44$, respectively (Table 1 ). The TL was 9.20 to 9.80 times greater than the ItL of the fish. The SmL was 1.90 to 2.20 times greater than the ItL of the fish with an average of 2.00 .

The regression equation between TL and SmL was $Y=-2.117+0.309 \times X \ldots \ldots$ (IX).

The regression equation between TL and ItL was $Y=0.482+0.102 \times X \ldots . .(X)$.

Where, $Y=S m L$ for equation (IX) and ItL for equation $(X) ; X=T L$.

\section{Glossogobius giuris}

Twenty fish samples of G. giuris ranges from $4.90 \mathrm{~cm}$ to $17.40 \mathrm{~cm}$ were selected for the study purpose. The mouth of the fishes were terminal but gradually narrow at the tip, and the outer portions of the jaws were muscular and in the inner parts were full of numerous fine and sharp teeth. Pharyngeal region was more or less rough. The pharynx was very short in size, oesophagus was very much unremarkable to comprise the hind part of the total alimentary canal. It was more or less thick with a rough inner surface. Immediately after the oesophagus a swollen stomach upto the mid part was found, which was gradually narrowed to the end.

It was more or less tubular in shaped. Intestine was originated from the post part of the stomach and reaches near to the rectum. The arrangement of the intestine was in such a manner that it found tubular shaped structure with a bend at the mid part of the intestine.

The TL, SL, ED, SmL and ItL of the fishes examined were $9.80 \pm 2.82,8.15 \pm 2.84,0.33 \pm$ $0.09,1.36 \pm 0.32$ and $3.00 \pm 0.81$, respectively (Table 1 ). It was observed that the TL was 3.00 to 4.50 times greater than the ItL with a mean of 3.20 and ItL was 2.10 to 2.50 times greater than that of the SmL with an average of 2.20.

The regression equation between $\mathrm{TL}$ and $\mathrm{SmL}$ was $\mathrm{Y}=0.638+0.073 \times \mathrm{X} \ldots . .(\mathrm{XI})$.

The regression equation between TL and ItL was $Y=0.595+0.245 \times \mathrm{X} \ldots . .(\mathrm{XII})$.

Where, $\mathrm{Y}=\mathrm{SmL}$ for equation (XI) and ItL for equation (XII); $\mathrm{X}=\mathrm{TL}$.

\section{Nandus nandus}

A total of twenty fishes of N. nandus ranges from $7.10 \mathrm{~cm}$ to $11.80 \mathrm{~cm}$. were selected for this study. The mouth types of the fishes were terminal but lower jaws comparatively elongated comprising of upper jaw. Both the jaws contain less dense sharp and fine teeth. The pharynx was comparatively long and flattened with a thicker walled. The eye diameter of the fish was ranged from $0.45 \mathrm{~cm}$ to $0.60 \mathrm{~cm}$.

The morphological structures of the alimentary canal of the fishes were more or less same. 
Oesophagus was observed comprising the smallest part of the alimentary canal. It was comparatively thick with a rough inner surface. Just after the oesophagus a well defined stomach was found, which was tapering and nipple form in the lower part. The intestine was originated from the post part of the stomach and positioned in right side of it. It was more or less coiling in pattern with a single bend at the middle portion of the intestine.

The TL, SL, ED, SmL and ItL of the fishes examined were $9.63 \pm 1.57,7.94 \pm 1.3,0.52 \pm 0.06$, $1.98 \pm 0.60$ and $7.03 \pm 1.49$, respectively (Table 1 ). The relationship between TL and ItL, and $\mathrm{SmL}$ and ItL were recorded. The TL was 1.20 to 1.50 times greater than the ItL of the fish with a mean of 1.36. The ItL was 2.90 to 3.20 times greater than that of SmL of the fish.

The regression equation between $\mathrm{TL}$ and $\mathrm{SmL}$ was $\mathrm{Y}=-0.925+0.302 \times \mathrm{X} \ldots$ (XIII).

The regression equation between TL and ItL was $\mathrm{Y}=-0.676+0.819 \times \mathrm{X} \ldots(\mathrm{XIV})$.

Where, $\mathrm{Y}=\mathrm{SmL}$ for equation (XIII) and ItL for equation (XIV); $\mathrm{X}=\mathrm{TL}$.

\section{Eleotris fusca}

Twenty fish samples of Boiragi, E. fusca ranges from $5.90 \mathrm{~cm}$ to $9.00 \mathrm{~cm}$ were selected for the study. The mouth type of the fish under studied was terminal. Outer side of the jaws was muscular and the inner parts were full of numerous short and fine teeth, pharyngeal region was more or less rough. The eye diameter ranged from $0.15 \mathrm{~cm}$ to $0.20 \mathrm{~cm}$. The pharynx was short in size. Oesophagus was undefined to comprise the least part of the total alimentary canal. Comparatively it was thick with somewhat rough inner surface. Immediately after the oesophagus a stomach with sac like structure was observed. The stomach was swollen in the mid part. The intestine was originated from the post part of the stomach and reaches to the rectum. The position of the intestine was tubular in shape with a bend at the mid part of it.

The TL, SL, ED, SmL and ItL of the fishes examined were $7.62 \pm 0.75,6.23 \pm 0.68,0.20 \pm$ $0.01,0.86 \pm 0.19$ and $4.93 \pm 0.88$, respectively (Table 1 ). It was observed that the TL was 1.40 to 2.36 times greater than the ItL with a mean of 1.45 and the ItL was 2.00 to 12.00 times greater than that of the SmL with an average of 5.70 .

The regression equation between $\mathrm{TL}$ and $\mathrm{SmL}$ was $\mathrm{Y}=-0.566+0.188 \times \mathrm{X} \ldots(\mathrm{XV})$.

The regression equation between TL and ItL was $Y=-0.772+0.747 \times X \ldots(X V I)$.

Where, $\mathrm{Y}=\mathrm{SmL}$ for equation $(\mathrm{XV})$ and ItL for equation $(\mathrm{XVI})$; $\mathrm{X}=\mathrm{TL}$.

\section{Anabas testudienus}

A total of twenty fishes of A. testudineus ranged from $7.10 \mathrm{~cm}$ to $11.60 \mathrm{~cm}$ were collected for study. The mouth types of the fishes were terminal with a little prolonged of lower jaws. Both the jaws bear a number of strong and comparatively less dense sharp fine teeth the pharynx was well defined and long with a thicker walled. The pharyngeal pad was also rough with blunt teeth. The eye diameters of the samples were ranged from 0.35 cut to $0.60 \mathrm{~cm}$. The mouth cavity was elongated towards the pharynx. Oesophagus was observed to comprise the least part of the whole alimentary canal. It was more or less thick 
with a rough inner surface. Immediately after the oesophagus a well defined sac like stomach was found, which was elongated and runs through out the body cavity. The arrangement of the intestine was in such a manner that firstly it formed a ' $U$ ' shaped and then ' $\mathrm{W}$ ' shaped. But the intestine was directly attached to the posterior part of the stomach. The intestine was found somewhat elastic and same in diameter from its origin to anus.

The TL, SL, ED, SmL and ItL of the fishes examined were $9.39 \pm 1.30,7.69 \pm 1.00,0.44 \pm$ $0.06,1.83 \pm 0.41$ and $5.98 \pm 0.93$, respectively (Table 1 ). The TL was 1.48 to 1.64 times greater than ItL of fish with a mean of 1.56. The ItL was 3.0 to 5.30 times greater than that of stomach with an average 3.3.

The regression equation between TL and SmL was $Y=-0.938+0.294 \times X \ldots . .(X V I I)$.

The regression equation between $\mathrm{TL}$ and ItL was $\mathrm{Y}=0.274+0.613 \times \mathrm{X} \ldots . .(\mathrm{XVIII})$.

Where, $\mathrm{Y}=\mathrm{SmL}$ for equation $(\mathrm{XVII})$ and ItL for equation $(\mathrm{XVIII}) ; \mathrm{X}=\mathrm{TL}$

\section{DISCUSSION}

As it was observed in the study, teeth were present in both jaws of all the species. So it was obvious that the fishes were carnivorous. Similarly, Lagler et al. (1977) noticed that in general teeth were existed in carnivorous. The mouth cavity was characterized by sac like elongated structure with swollen mid part. The large volume of mouth cavity was observed due to its food habits. To handle this large prey it needs large mouth cavity. The inner surface of the mouth cavity was rough which was however due to presence of numerous taste buds (Sanderson et al., 1991). The taste buds are assumed to be used for selecting foods. The role of the taste buds in selection and detection of food particles in fishes have been observed by several scientists (Sibbing and Urive, 1985; Sibbing, 1987; Hlohowskyj et al., 1989). Again the large bucco-pharyngeal region enriched with large number of mucous cells in case of carnivorous fish was reported by Shamardina, 1957; Squires, 1957; Sinha and Moitra, 1975.

The development and arrangement of the pharyngeal teeth of all the fishes studied under present experiment was similar to that described by Teplova and Teplov (1953). They observed that modification of the last gill arch caused the formation of pharyngeal teeth. The teeth were strong, large and pointed at the tip, which might be used for grasping mid chopping the food particles. According to Lagler et al. (1977), the pharyngeal teeth were sharp in carnivorous fishes which supported the findings of the present study and thereby it was suspected that the fishes were carnivorous in feeding behaviour. According to Hora (1945) and Vasnetsov (1953), the structures of the pharynx of these species were closely related to feeding behaviour of the fish described by them.

Oesophagus was found to comprise the smallest portion of the alimentary canal with rough inner surface and opened to the stomach. It was Happy in structure so that could be helpful for the engulfment of larger amount of food. Khulsharshtha (1975) worked on 
some freshwater fishes and found that the oesophagus was short, tubular structure and was not distinguishable externally from the rest of the gut. Islam (1985) found that the oesophagus of Mystus gulio was short and directly open into the stomach. The great dispensability of the oesophagus has been reported by Lagler et al. (1977).

The structures of the stomach of all the experimental fishes were more or less same which were found to be large, sac like with thick wall and rough inner surface. Elongated structure was assumed to give long passage for the food eaten for proper digestion. The thickend wall with muscular structure was most probably helped in grinding the food particles. Mookerjee and Das (1945) observed that the size of the stomach in fishes was closely related to the feeding behaviour and particularly to the size of the prey. They also stated that predators have a large mouth short and few gill rackers, a large stomach, usually a large number of pyloric caecae and a short intestinal tract which is very similar to the findings of the present study. Vladimirov (1957) stated that in fishes which swallow large prey or else consume large amount of foods at the same time. The stomach was usually large.

The coiling pattern of the intestine of the fishes studied varied species to species. The least or no coiling pattern of intestine was found in case of $X$. cancila, and very little coiling patterns were observed in the intestine of J. koitor, M. vittatus and E. fusca in comparison with the rest of the species studied. Perhaps, it might be caused for strong acid secretion during their digestion in case of less coiled intestinal fishes. But most of the species the anterior portion of the intestine was thick walled and the posterior intestine was thin. Islam (1985) also found that the interior intestine of M. gulio was with thick wall and the posterior intestine was with thin wall which was very much similar with the findings of the present study. From the results it was observed that intestinal length was larger than that of the stomach length of all the species except X. cancila. Among the species intestinal length was 1.50 to 5.90 times greater than the stomach length but in case of X. cancila stomach length was 1.80 times greater than that of the intestinal length. The total length of the fish studied was greater than that of the intestinal length. Among the 10 species studied total length was, 1.30 to 9.50 times greater than the intestinal length of the fish. The similar result was observed by Nikolsky (1963). He stated that in carnivorous fishes the intestine comprises less than $100 \%$ of the body length of the fish and more than $100 \%$ in herbivorous. He also stated that in different numbers of the Cichlidae the predator Cichla temensis has large stomach and short intestine while the herbivore, Tilapia heudlotia had a small stomach and a long intestine. Lagler et al. (1977) observed that the intestine was shortened in carnivores, perhaps because meaty food could be digested more readily than vegetables one's and it was often elongated and arrange in many-folds in predominately herbivorous species.

\section{CONCLUSION}

Fisheries resources play important roles in poverty alleviation, employment generation, nutrition and foreign currencies earning, traditions and food habit of the people of Bangladesh. It is endowed with diversified fisheries resources enriched with variety of 
indigenous fish species. Due to different man-made and natural reasons, the Bangladesh fisheries are now under great threat. To improve the production and aquatic biodiversity, biological management of natural water bodies as well as new fish species for aquaculture should be introduced. During the present study, nine fishes were examined to study the morphology associated with the digestive systems of the chosen fishes and to study the relationship between the body length and the gut length.

As it was found, well-defined sharp teeth were present on both jaws of the fishes examined. It was also noticed that the fishes had rough surface pharyngeal pads. It was observed that the total length was 1.28 to 1.72 times greater than that of the intestinal length of J. koitor and intestinal length was 5.45 to 6.02 times greater than that of the stomach length. The total length of $C$. orientalis was 2.90 to 3.17 times greater than the intestinal length. The intestinal length was 1.30 to 1.70 times greater than that of the stomach of the fish. The total length of $C$. punctatus was 2.22 to 2.70 times greater than the intestinal length. The intestinal length was recorded 1.70 to 2.10 times greater than that of the stomach. The total length of $M$. vittatus was 2.00 to 2.40 times larger than that of the intestine. The intestinal length was 3.60 to 4.10 times greater than that of the stomach length. The total length of X. cancila was 9.20 to 9.80 times greater than the intestinal length. The stomach length was 1.90 to 2.20 times greater than the intestinal length of the fish. The total length of G. giuris was 3.00 to 4.50 times greater than the intestinal length and the intestinal length was 2.10 to 2.50 times greater than that of the stomach length. The total length of $N$. nandus was 1.20 to 1.50 times greater than the intestinal length. The intestinal length was 2.90 to 3.20 times greater than that of stomach length. The total length of $E$. fusca was 1.40 to 2.36 times greater than the intestinal length and the intestinal length was 2.00 to 12.00 times greater than that of the stomach length. The total length of $A$. testudineus was 1.48 to 1.64 times greater than intestinal length. The intestinal length was 3.0 to 5.30 times greater than that of stomach length.

Finally, as it was identified, all fishes examined were carnivorous, therefore, to rear these fish live small animals or supplementary feeds of animal origin will be required. Further research should be undertaken to find out the impact of stomach length and intestine length on supplementary feeds and growth rate of the fishes.

\section{ACKNOWLEDGEMENT}

The authors sincerely express their heartiest gratitude and profound regards to the honourable teachers, Professor Dr. Md. Mohsin Ali and Professor Dr. S. M. Rahmatullah, Department of Aquaculture, Bangladesh Agricultural University, Mymensingh for their scholastic guidance, encouragement, valuable advice, worthy criticism throughout the research period.

\section{REFERENCES}

DoF. 1995. Fisheries Survey System Project, Department of Fisheries, Ramna, Dhaka, p. 80. 
Hlohowskyj, C. P., Couburn, M. M. and Lavender, R. M. 1989. Comparison of a phyryngeal filtering apparatus in seven species of the herbivorous Cyprinic Genus, Hybognathus (Pisces: Cyprinidae). Copeia, 1989: 172-183.

Hora, S. 1945. Analysis of the factors influencing the spawning of carps. Proc. Nat. Inst. Sa. India. 11, No. 3.

Islam, M. A. 1985. Studies on the morphology and histology of the alimentary canal of Mystus gulio (Ham). Bangladesh J. Zool., 13(1): 7-11.

Khulshrestha, S. D. 1975. Histomorphology of the taste receptors of some freshwater fishes. Indian J. Fish., 22(1 \& 2): 143-170.

Lagler, K. F., Bardach, J. E., Miller, R. R. and Passino, D. R. M. 1977. Ichthyology. 2nd Edn. John Wiley and Sons, New York, pp. 129-170.

Mookerjee, H. K. and Das, B. K. 1945. Gut of the carnivorous and herbivorous fishes in relation to their food at different stages of life. Proc. 32 ${ }^{\text {nd }}$ Indian Sci. Congr., Part III. Abstracts: 109.

Nikolsky, G. V. 1963. The ecology of fishes. Academic Press. London and New York. p. 352.

Rahman, A. K. A. 1989. Freshwater Fishes of Bangladesh. The zoological society of Bangladesh. Department of Zoology, University of Dhaka, p. 412.

Sanderson, S. C., Cech, Jr. J. J. and Patterson, M. R. 1991. Fluid dynamics in suspension feeding of Black fish. Science. 251: 1346-1348.

Shamardina, I. P. 1957. The developmental stages of the pike. Trud. Inst. Morf. Zhiv. No. 16.

Sibbing, F. A. 1987. The role of taste in the feeding mechanism of the carp (Cyprinicae). Taste olfac. Ann. NY. Acad Sci., 1987: 612-615.

Sibbing, F. A. and Urive, R. 1985. Regional specializations in the oro-phryngeal wall and food processing in the carp (Cyprinus carpio L.). Neth. J. Zool., 35: 377-422.

Sinha, G. M. and Moitra, S. K. 1975. Functional morpho-histology of the elementary canal of an Indian freshwater major carp, Labeo rohita (Hamiltion) during its different life history stages. Anat. Anz. Bd. 138: 222-239.

Teplova, V. N. and Teplov, V. P. 1953. The feeding of the pike in the upper Pechora basin. Vop. Ikht. No. 1.

Vasnetsov, V. V. 1953. The unity of the ecology of the species in fishes. "Essays on General Problems in Ichthyology" (Ocherki po obshchem voprosain ikilitiologi). USSR Academy of Sciences Press.

Vladimirov, Y. I. 1957. On the biological classification of fishes into migratory and fluvialmigratory types. Zool. Zh. 36(8): 4848-52. 